\title{
Dysfunctions of neuronal and glial intermediate filaments in disease
}

\author{
Ronald K.H. Liem ${ }^{1}$ and Albee Messing ${ }^{2}$
}

\begin{abstract}
1Department of Pathology and Cell Biology, Taub Institute for Research on Alzheimer's Disease and the Aging Brain, Columbia University College of Physicians and Surgeons, New York, New York, USA.

2Waisman Center and Department of Comparative Biosciences, University of Wisconsin, Madison, Wisconsin, USA.
\end{abstract}

\begin{abstract}
Intermediate filaments (IFs) are abundant structures found in most eukaryotic cells, including those in the nervous system. In the CNS, the primary components of neuronal IFs are $\alpha$-internexin and the neurofilament triplet proteins. In the peripheral nervous system, a fifth neuronal IF protein known as peripherin is also present. IFs in astrocytes are primarily composed of glial fibrillary acidic protein (GFAP), although vimentin is also expressed in immature astrocytes and some mature astrocytes. In this Review, we focus on the IFs of glial cells (primarily GFAP) and neurons as well as their relationship to different neurodegenerative diseases.
\end{abstract}

\section{Introduction}

Intermediate filaments (IFs) are $8-10 \mathrm{~nm}$ structures that, together with microtubules (24-26 nm) and microfilaments (6-8 nm), form the cytoskeleton that is present in nearly all eukaryotic cells. In the nervous system, IFs are present in neurons and astrocytes, although they are absent from oligodendrocytes, which form the myelin sheath in the CNS. IF proteins are structurally related and part of a large family of proteins that includes keratins and nuclear lamins (see Figure 1 for a diagram of neuronal and glial cell IF proteins).

The major IF protein in astrocytes is glial fibrillary acidic protein (GFAP), although there are lower levels of other IFs, including nestin, vimentin, and synemin. Recent studies have revealed the presence of multiple isoforms of GFAP (Figure 1), which may be differentially expressed in reactive versus resting astrocytes. To date, the only specific connections between any of these astrocytic IF proteins and particular diseases remain those between the most abundant $\alpha$ isoform of GFAP and the leukodystrophy/ neurodegenerative disorder Alexander disease. In the CNS, the major neuronal IF proteins are the neurofilament triplet proteins (NFTPs) - low-molecular weight neurofilament subunit (NFL) (68 kDA), middle-molecular weight neurofilament subunit (NFM) (160 kDA), and high-molecular weight neurofilament subunit (NFH) (205 kDA) - and $\alpha$-internexin. In the peripheral nervous system (PNS), peripherin is also expressed along with the NFTPs (reviewed in ref. 1). In this Review, we discuss the role of mutations in neuronal and glial cell (mainly GFAP) IF protein-encoding genes in the formation of intermediate filamentous accumulations and the pathogenesis of neurodegenerative diseases.

\section{Astrocytes, IFs, and disease}

The causal role of mutations in GFAP and Alexander disease has been well reviewed during the past few years $(2,3)$. Here, we con-

Conflict of interest: The authors have declared that no conflict of interest exists. Nonstandard abbreviations used: ALS, amyotrophic lateral sclerosis; CMT, Charcot-Marie-Tooth disease; CSF, cerebrospinal fluid; GAN, giant axonal neuropathy; GFAP, glial fibrillary acidic protein; IF, intermediate filament; MTMR2, myotubularin-related protein $2 ; \mathrm{NCV}$, nerve-conduction velocity; NEFL, gene encoding NFL $\mathrm{NFH}$, high-molecular weight neurofilament subunit; NFL, low-molecular weight neurofilament subunit; NFM, middle-molecular weight neurofilament subunit; NFTP, neurofilament triplet protein; NIFID, neuronal IF inclusion disease; PNS, peripheral nervous system; SOD1, superoxide dismutase 1.

Citation for this article: J. Clin. Invest. 119:1814-1824 (2009). doi:10.1172/JCI38003. centrate on newly published aspects of GFAP and Alexander disease research as well as on other topics relating to GFAP and disease that have not been addressed by previous reviews.

GFAP mutations and Alexander disease. Alexander disease, first described in 1949 (4), is a rare leukodystrophy (disorder characterized by failure or loss of myelin, leading to progressive degeneration of the white matter of the brain) of unknown incidence that nearly always results from dominantly acting mutations in the coding region of GFAP (5). Most patients experience their first symptoms (such as seizures or developmental delays) before they are two years old. The disease is characterized by dramatic loss of white matter in the frontal lobes, and the patients suffer progressive deterioration, with death before the age of 6 . Although this is the most common form of Alexander disease, later onset and milder forms of the disease also exist, sometimes without any white matter defects at all. The hallmark pathological feature is the presence of protein aggregates known as Rosenthal fibers within the cytoplasm of astrocytes, especially those in subpial, subependymal, and perivascular locations (Figure 2). These fibers are complex ubiquitinated stress protein inclusions that contain a still undefined number of constituent proteins in addition to the mutant GFAP.

To date, no GFAP mutations that lead to an absence of GFAP or truncated protein have been found in Alexander disease patients, and the mutations that cause Alexander disease lead to the synthesis of GFAP variants with subtle amino acid changes that are thought to act in a toxic gain-of-function fashion. The $\alpha$ isoform of human GFAP contains 432 amino acids (Figure 1), and presently 91 mutations affecting 62 amino acids have been associated with Alexander disease. A complete listing of all published (and some unpublished) mutations is maintained at the Waisman Center of the University of Wisconsin-Madison (http://www.waisman.wisc. edu/alexander/mutations.html). A separate listing of GFAP mutations and polymorphisms is maintained as part of the Human Intermediate Filament Database (http://www.interfil.org/) (6), which includes fewer mutations than the Waisman database but provides more detail about each one.

As described in previous reviews, the Alexander disease-associated GFAP mutations seem to lead to accumulations of GFAP protein, and it may be this elevation of protein that is more deleterious to the astrocytes than the mutant protein itself. The specific aspects of astrocyte functions that are compromised by the mutations have not yet been discovered. However, the 


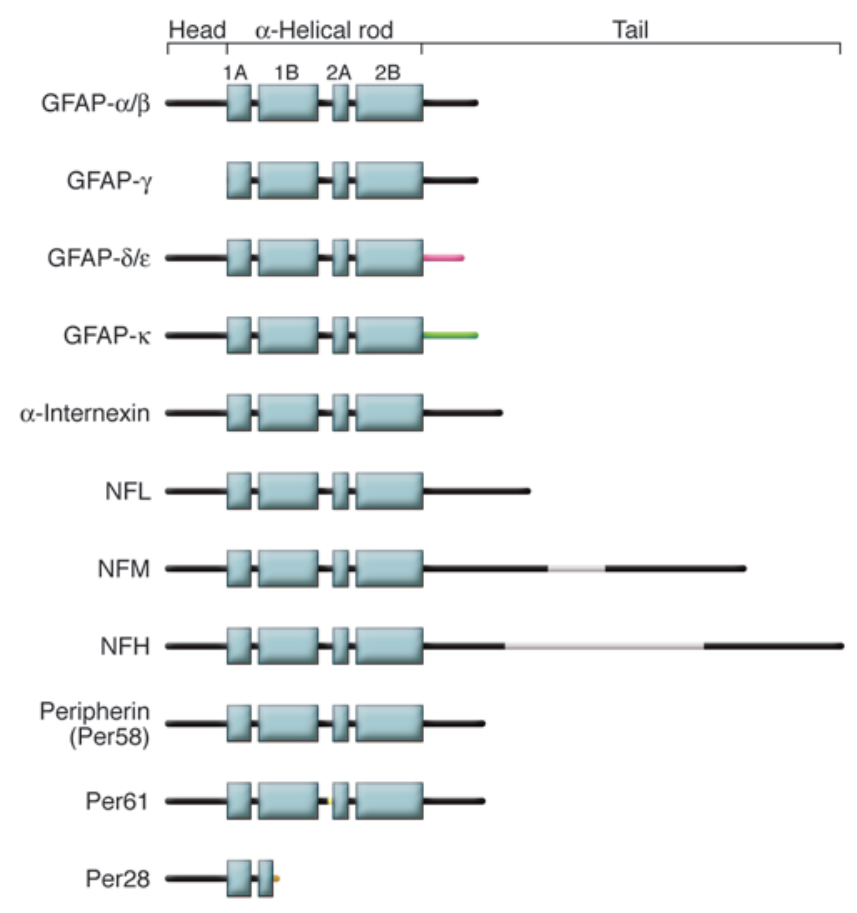

mechanisms leading to protein accumulation are starting to be revealed. As with other protein aggregation disorders of the CNS, several lines of evidence suggest that decreased degradation plays a key role. Studies in cell lines, animal models, and human tissues all indicate activation of several stress-response pathways within astrocytes that express mutant GFAP (7-9). For instance, expression of the R239C form of GFAP, which is one of the most common Alexander disease-associated mutations, activates JNK and p38 kinases, with resulting impairment of proteasomal function (9). Decreased proteasomal activity has also been found in primary cultures of astrocytes prepared from mice expressing the $\mathrm{R} 236 \mathrm{H}$ mutation (equivalent to the $\mathrm{R} 239 \mathrm{H}$ human mutation) as a knockin at the endogenous Gfap locus (10). How many substrates besides GFAP are affected by this inhibition of proteasomal activity is not yet known. Since GFAP has a long halflife in vivo (11), interfering with protein degradation could have prolonged effects. The oxidative stress that is clearly present in astrocytes expressing GFAP mutants also likely leads to increased transcription from the GFAP gene (12), so that both increased transcription and decreased degradation could promote protein accumulation. The mechanisms leading to increased transcription have yet to be determined.

Other proteins of importance for neurodegenerative disease, such as $\alpha$-synuclein, are degraded by both proteasomal and autophagic pathways (13). Although autophagy was not previously thought to contribute to GFAP degradation, it appears that this pathway is actually enhanced in the context of mutant forms of GFAP associated with Alexander disease and by GFAP accumulation (14). These changes were evident not only in transfected cell lines but also in tissues and cells from mouse knockin models of Alexander disease and the brains of patients with Alexander disease. Morphologically, microtubule-associated protein 1 light chain 3 (LC3), a marker of autophagosomes, localizes close to Rosenthal fibers, and EM studies of cell lines, mouse tissues, and one patient with Alexander disease have revealed membrane-

\section{Figure 1}

The major IF proteins in neurons and glial cells. A "typical" IF protein consists of an $\mathrm{N}$-terminal head region, a rod region that contains four $\alpha$-helical regions (helices $1 \mathrm{~A}, 1 \mathrm{~B}, 2 \mathrm{~A}$, and $2 \mathrm{~B}$ ), and a C-terminal tail region. Different isoforms of GFAP are shown: GFAP- $\alpha$ and GFAP- $\beta$ are full-length GFAP proteins; the mRNAs encoding these two proteins differ in the 5' UTR. GFAP- $\gamma$ is encoded by an mRNA that has an alternate start site and is missing exon 1. The mRNAs encoding GFAP- $\delta$, GFAP- $\varepsilon$, and GFAP $-\kappa$ are generated by alternative splicing of intron 7 , with variable use of exon $7+$, to create proteins with different $C$-terminal tail sequences. Only single isoforms of $\alpha$-internexin, NFL, NFM, and NFH are shown. The gray areas in NFM and NFH contain multiple phosphorylation sites. Full-length peripherin (Per58) is shown as well as Per61, a mouse isoform that retains intron 4 (96), and Per28, which is a mouse and human isoform that retains introns 3 and 4 , resulting in a truncated peripherin (97).

bound structures similar to autophagosomes and autolysosomes next to Rosenthal fibers (14). Autophagy was also recently shown to be an adaptive response in a cardiomyopathy resulting from mutations in $\alpha \mathrm{B}$-crystallin associated with aggregation of another IF protein, desmin (15).

The impact of autophagy on GFAP levels is indicated by several observations. Treatment of transfected U251 human astrocytoma cells with an inhibitor of autophagy led to further elevation of GFAP levels, while induction of autophagy reduced GFAP levels as well as the number of inclusions found in the cells (14). These changes in autophagy did not have measurable effects on global protein degradation, implying some level of selectivity for GFAP and perhaps other components of the aggregates. In the model proposed by the authors of this study (14), the stimulation of autophagy is not enough to counteract the effects of proteasomal inhibition, so GFAP accumulation ensues. Of potential therapeutic significance, the autophagy response seemed to be regulated, at least in part, by mammalian target of rapamycin (mTOR) and was enhanced in the presence of the mTOR inhibitor rapamycin. Hence, rapamycin and its analogues, currently the topic of much clinical investigation for other disorders (16), should be evaluated for possible utility in Alexander disease.

The mutant forms of GFAP associated with Alexander disease display a shift in the equilibrium from the soluble (i.e., monomers to small oligomers) toward insoluble (assembled filaments or aggregates) pools (17) and drag IF-associated proteins such as $\alpha B$-crystallin and probably plectin in the same direction $(18,19)$. Among the minor isoforms of GFAP, GFAP- $\delta$ (Figure 1) seems preferentially expressed in the same populations of astrocytes that contain the most Rosenthal fibers (i.e., subpial and periventricular astrocytes) (20). Recent studies show that GFAP- $\delta$ alters the binding of $\alpha B$-crystallin to GFAP filaments (18). In normal human spinal cord, GFAP- $\delta$ accounts for less than $10 \%$ of the total GFAP. Whether GFAP- $\delta$ is disproportionately increased in Alexander disease tissue, further affecting filament solubility and association with IF-associated proteins, remains to be determined.

The stress response that is activated in astrocytes in individuals with Alexander disease could be both deleterious and beneficial. Studies in cell culture suggest that such astrocytes are compromised in their ability to respond to further stress, such as from camptothecin or hydrogen peroxide $(9,10)$. However, very recent work indicates that enhancing the upregulation of astrocytic $\alpha B$-crystallin can offer dramatic rescue from the otherwise lethal effects of GFAP mutation and excess (21). 
A

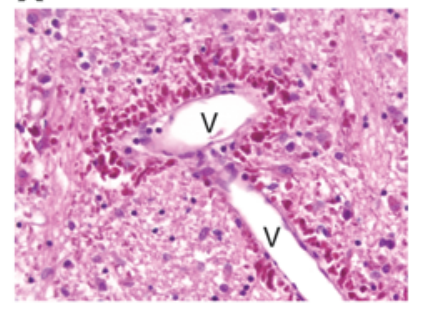

c

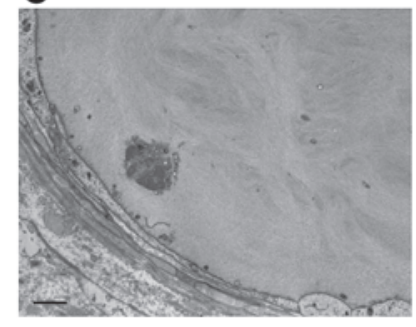

B

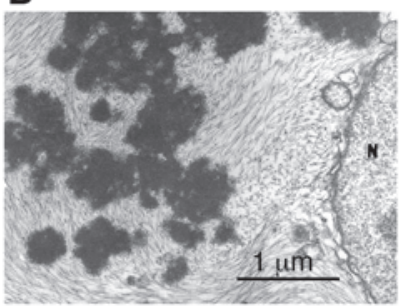

D

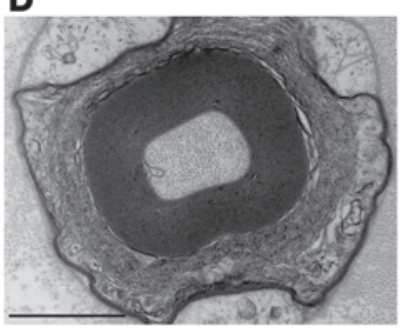

GFAP and potential links to gigaxonin? A protein with functional significance for both neuronal and glial IFs is gigaxonin. Mutations in gigaxonin are responsible for the disorder giant axonal neuropathy (GAN) (OMIM 250850) (22, 23). Gigaxonin functions as a substrate adaptor for a Cul3-E3 ubiquitin ligase complex and facilitates proteasomal degradation of several cytoskeleton-associated proteins (24). The mechanism by which loss-of-function mutations in gigaxonin interfere with the IF system is not known, yet a hallmark feature in individuals with GAN is the accumulation of neuronal IFs in axons of the PNS and CNS (25-27). Abnormalities are also seen in other IFs and outside the nervous system (26, $28,29)$. Within the CNS, Rosenthal fibers have been described in several patients with $\operatorname{GAN}(25,27,30)$. It is intriguing to speculate that loss of gigaxonin affects GFAP, causing it to accumulate and aggregate in a manner similar to its effects on other IFs, and may even produce Alexander disease-like pathology. A recent authoritative review of the MRI features of leukodystrophies comments on the similarities between GAN and Alexander disease with respect to lesions in the white matter (31).

A gigaxonin-deficient mouse has been generated (32). These mice have no obvious clinical symptoms and exhibit a normal lifespan. The levels of the neuronal IF proteins and vimentin were all modestly increased in the CNS, but there was no apparent change in the levels of GFAP. IF-containing aggregates formed preferentially in cerebral cortex and thalamus and were composed primarily of $\alpha$-internexin and hypophosphorylated NFH. Only minimal changes in axon caliber were found, and no giant axons were ever observed, although there was a small loss of motor axons in ventral roots, with corresponding evidence of mild denervation in muscle. Whether these mice have any astrocyte inclusions similar to those in individuals with GAN remains to be established.

GFAP as a biomarker in cerebrospinal fluid and serum. Apart from its role as a causal element in disease, it is worth considering how simply measuring GFAP levels in various body fluids might be useful for monitoring and diagnosing disease. Cerebrospinal fluid (CSF) has long been exploited as a relatively noninvasive way to biopsy the CNS. GFAP is normally present at low levels in this fluid, thus requiring the development of sensitive methods of detection, typically by sandwich ELISA (33). Direct comparisons of the absolute levels of GFAP found in the CSF by different labo-

\section{Figure 2}

Morphological features of glial and neuronal protein aggregates in Alexander disease and CMT. (A) Rosenthal fibers concentrated in the astrocytic endfeet surrounding a blood vessel $(\mathrm{V})$ in the brain stem of a 1-year-old child with Alexander disease. H\&E stain, paraffin section (reproduced with permission from Elsevier [102]). Original magnification, $\times 62$. (B) Rosenthal fibers surrounded by IFs in an astrocyte cell body from a 17-month-old child with Alexander disease, viewed by transmission electron microscopy (reproduced with permission of Wiley-Liss Inc., a subsidiary of John Wiley \& Sons Inc. [103]). $\mathrm{N}$, nucleus. (C) Sural nerve biopsy from a CMT patient with an L286P mutations in NFL. The figure shows a giant axon with a cluster of organelles (arrow) and irregular whorls of neurofilaments. (D) Sural nerve biopsy of a CMT patient with an NFL del322C-326N mutation. The figure shows a fiber whose axoplasm consists almost exclusively of microtubules; note the loosening of the external myelin lamellae (panels $\mathbf{C}$ and $\mathbf{D}$ were reproduced with permission from Brain: a journal of neurology [79]). Scale bars: $1 \mu \mathrm{m}$ (B); $2 \mu \mathrm{m}$ (C and D).

ratories have been difficult, with various groups reporting mean levels in healthy individuals ranging from below $10 \mathrm{ng} / \mathrm{l}$ to nearly $4000 \mathrm{ng} / 1$ (34-36). Sexual phenotype seems to have no effect (36, $37)$, and there is a dispute about whether age is a confounding variable $(36,38)$. Details of methodology and definition of the control groups may account for some of these differences (see ref. 36 for a good discussion on this point), but these discrepancies also highlight the importance of each laboratory establishing its own reference range. Why GFAP should be present in the CSF of healthy individuals is an open question, as astrocytes do not secrete the protein (39). Its presence presumably reflects some baseline level of astrocyte death, with release of cytoplasmic contents into the extracellular space.

With these caveats in mind, it appears that GFAP levels in CSF are elevated in association with a number of neurological conditions reflecting a wide range of etiologies, including vascular, traumatic, developmental, genetic, inflammatory, neoplastic, and degenerative (Table 1) (a more comprehensive listing on this topic is provided in Supplemental Table 1). In some situations, the GFAP level is evaluated in comparison with other biomarkers thought to be indicative of neuronal damage, such as the presence of neurofilaments in CSF $(34,40)$. Generally, the elevations are modest in slowly progressive conditions such as dementia and MS and higher but transient in other conditions such as vascular accidents, trauma, and infection. In some situations, the level of GFAP in CSF may have prognostic value (41-43). For instance, in patients with subarachnoid hemorrhage, GFAP levels 6 days after the event were approximately 8 -fold higher in nonsurvivors compared with survivors (43). In other conditions, GFAP levels in CSF seem to drop in response to treatment, for example, in patients with neuromyelitis optica given corticosteroid therapy (44). It should be noted that the measurement of GFAP has yet to achieve the status of clinical application for any of these conditions.

Among the disorders showing the highest levels of GFAP in the CSF are two in which astrocytes are considered either the direct target or cause of disease, neuromyelitis optica and Alexander disease. The hallmark feature of neuromyelitis optica is the presence of antibodies specific for the relatively astrocyte-specific protein aquaporin-4, a membrane-associated water channel that plays a critical role in volume regulation and the evolution of edema in response to injury. In one cohort of ten patients with neuromyelitis optica, all had elevations of GFAP in the CSF, and 
Table 1

GFAP levels in the CSF of individuals with neurological conditions reflecting a wide range of etiologies are elevated

\begin{tabular}{|c|c|c|c|c|c|c|c|c|}
\hline \multirow[t]{2}{*}{ Condition } & \multicolumn{3}{|c|}{ Controls } & \multicolumn{3}{|c|}{ Patients } & \multirow[t]{2}{*}{ Site } & \multirow[t]{2}{*}{ Ref. } \\
\hline & $n$ & Mean \pm SD (ng/l) & Range & $n$ & Mean \pm SD (ng/l) & Range & & \\
\hline \multicolumn{9}{|l|}{ Vascular } \\
\hline Vasculitis & $N R$ & $\begin{array}{c}{[<750 \text { younger }]^{A}} \\
{\left[<1,250 \text { older }^{A}\right.}\end{array}$ & $N R$ & 32 & $10,791 \pm 7646$ (SEM) & $N R$ & L & 104 \\
\hline Ischemic infarcts & 18 & $7404 \pm 2099$ (SEM) & $4,138-11,518$ & 25 & $16,005 \pm 17,302$ (SEM) & $N R$ & L & 105 \\
\hline SA hemorrhage & $N R$ & $95 \%<9$ (lumbar) & NR & 5 & $18,950 \pm 16,078$ & $1,550-40,630$ & V & 36 \\
\hline \multicolumn{9}{|l|}{ Trauma } \\
\hline TBI & $N R$ & $95 \%<9$ (lumbar) & $N R$ & 11 & $16678 \pm 15022$ & $515-43,730$ & V & 36 \\
\hline \multicolumn{9}{|l|}{ Developmental } \\
\hline Autism & 10 & $67 \pm 17$ (SEM) & $16-163$ & 47 & $185 \pm 20$ (SEM) & $\sim 16-600$ & L & 38 \\
\hline Hydrocephalus & $N R$ & $700 \pm 900$ (lumbar) & NR & $\begin{array}{l}41 \\
27 \\
12\end{array}$ & $\begin{array}{r}\text { Gr } 1: 19,000 \pm 26,000 \\
\text { Gr 2: } 20,000 \pm 21,000 \\
\text { Gr } 3: 2.2 \times 10^{6} \pm 2.96 \times 10^{6}\end{array}$ & $N R$ & V & 46 \\
\hline Neonatal asphyxia & 8 & 538 median & $458-1,051$ & 22 & 1,428 median & $427-49,706$ & L & 34 \\
\hline Premature birth & 10 & 222 median & $87-554$ & $\begin{array}{l}17 \\
10\end{array}$ & $\begin{array}{l}\text { Normal preterm } 106 \text { (NS) } \\
\text { Abnormal preterm } 576\end{array}$ & $\begin{array}{c}15-362 \\
265-16,000\end{array}$ & L & 41 \\
\hline \multicolumn{9}{|l|}{ Genetic } \\
\hline Alexander disease & $N R$ & {$[<175]^{\mathrm{A}}$} & NR & 3 & NA & $4,760-30,000$ & $N R$ & 45 \\
\hline \multicolumn{9}{|c|}{ Infectious and inflammatory } \\
\hline Multiple sclerosis & 25 & $250 \pm 34$ & $125-450$ & $\begin{array}{l}21 \\
15\end{array}$ & $\begin{array}{l}\text { SP } 375^{B} \\
\text { PP } 400^{B}\end{array}$ & $\begin{array}{l}130-625^{\mathrm{B}} \\
130-900^{\mathrm{B}}\end{array}$ & $N R$ & 42 \\
\hline Meningitis/encephalitis & 25 & NR & $\sim 100-1,300$ & 13 & NR & $\sim 1,000-30,000^{\mathrm{B}}$ & $\mathrm{L}$ & 106 \\
\hline Neuromyelitis optica & 5 & $600 \pm 300$ & $300-1,000$ & 10 & $7,666 \pm 15,267 \mathrm{C}$ & $8,000-80,000,000^{B}$ & NR & 44 \\
\hline Guillain-Barré & 30 & 330 median & NR & $\begin{array}{c}12 \\
9\end{array}$ & $\begin{array}{l}\text { AIDP } 350 \text { median (NS) } \\
\text { Axonal } 550 \text { median }\end{array}$ & NR & NR & 49 \\
\hline \multicolumn{9}{|l|}{ Degenerative } \\
\hline Dementia & 39 & $569 \pm 265$ & $N R$ & $\begin{array}{l}29 \\
20\end{array}$ & $\begin{array}{c}\text { AD type } 1,081 \pm 561 \\
\text { Vascular } 1,270 \pm 1,142\end{array}$ & $N R$ & L & 107 \\
\hline Dementia & $\begin{array}{c}13 \\
9 \\
8\end{array}$ & $\begin{array}{c}2,960 \pm 1,040 \text { young } \\
2,800 \pm 1,460 \text { adult } \\
3,990 \pm 1,590 \text { elderly }\end{array}$ & $N R$ & 27 & AD $8,960 \pm 7,800$ & $N R$ & $N R$ & 35 \\
\hline Dementia & NR & $95 \%<9$ & NR & 68 & $1,374 \pm 11,098$ & $<5-91,540^{D}$ & L & 36 \\
\hline \multicolumn{9}{|l|}{ Miscellaneous } \\
\hline NPH & 40 & $637 \pm 295$ & NR & 65 & $1,116 \pm 1,085$ & NR & L & 40 \\
\hline NPH & $N R$ & $95 \%<9$ (lumbar) & NR & 12 & $1,197 \pm 1,226$ & $<5-2970$ & V & 36 \\
\hline
\end{tabular}

All values have been converted to $\mathrm{ng} / \mathrm{l}$ to facilitate comparison. Unless otherwise noted, values are given as mean $\pm \mathrm{SD}$. $\mathrm{AD}, \mathrm{Alzheimer}$ disease; Gr, grade; NPH, normal pressure hydrocephalus; SP, secondary progressive; PP; primary progressive; SA, subarachnoid; TBI, traumatic brain injury; NR, not reported. Site refers to lumbar (L) or ventricular (V) points of collection of CSF if specified by the authors - others are most likely lumbar. AValues for controls surrounded by brackets were derived from a prior study, literature, or manufacturer using the particular assay. ${ }^{\mathrm{B} D a t a}$ were presented in graphical form, from which these are estimated values. CWhether SD or SEM was not specified. DThe outlier value at the high end was from a patient who had autopsyproven Creutzfeldt-Jakob Disease.

several had extraordinarily high levels (44). These studies further implicate damage to astrocytes as an important feature of the disease. For Alexander disease, GFAP levels in CSF have now been reported for three patients (45). This is a very small set of patients, and the degree to which GFAP levels in CSF were elevated was variable. However, since GFAP is the root cause of Alexander disease and elevations of GFAP within astrocytes are thought to be central to the pathogenesis (see above), its measurement might prove especially valuable in this particular condition for assessing either severity or progression. For instance, the highest levels in this study were found in patient 2 , who although intermediate in terms of age of onset, was rapidly deteriorating at the time of biopsy.
As might be expected with an intact blood-brain barrier, GFAP is usually undetectable in serum (despite its presence in CSF) in the absence of disease or injury. Nevertheless, in certain settings, GFAP does appear in serum, especially in relation to trauma and vascular accidents (Table 2) (a more comprehensive listing on this topic is provided in Supplemental Table 2). Simultaneous determinations of both CSF and serum GFAP levels has only been performed in two studies (in both cases when no significant changes were noted for serum for the diseases under study), and the mean levels for serum were approximately three- to six-fold lower than in CSF $(46,47)$. GFAP has only been detected in urine once, in a child who died of septic shock (48), although the exact GFAP levels were not given. 
Table 2

GFAP appears in the serum under certain circumstances

\begin{tabular}{|c|c|c|c|c|c|c|c|}
\hline \multirow[t]{2}{*}{ Condition } & \multirow{2}{*}{$\begin{array}{c}\text { Controls } \\
n\end{array}$} & \multirow[b]{2}{*}{ Mean \pm SD (ng/l) } & \multicolumn{3}{|c|}{ Patients } & \multirow[b]{2}{*}{ Range } & \multirow[t]{2}{*}{ Ref. } \\
\hline & & & Range & $n$ & Mean \pm SD (ng/l) & & \\
\hline \multicolumn{8}{|l|}{ Vascular } \\
\hline Ischemic stroke & 46 & $95 \%<40$ & $14-660$ & 22 & $2,000 \pm 1,500(\mathrm{SEM})^{\mathrm{A}}$ & NR & 108 \\
\hline Hemorrhagic stroke & $\begin{array}{c}52 \\
3\end{array}$ & $\begin{array}{c}<1.8 \\
3.8-7.2\end{array}$ & NR & 42 & $112 \pm 477$ & $0-3,096$ & 109 \\
\hline Subarachnoid hemorrhage & 81 & $<150$ & NR & 116 & 1130 mean; 330 median & $30-34,430$ & 110 \\
\hline \multicolumn{8}{|l|}{ Trauma } \\
\hline Traumatic brain injury & 218 & $\begin{array}{c}61 \pm 44 \\
95 \%<150\end{array}$ & $N R$ & 59 & $\begin{array}{c}4,520 \pm 8,690 \\
1,170 \text { median }\end{array}$ & $140-49,580$ & 111 \\
\hline \multicolumn{8}{|l|}{ Developmental } \\
\hline Hydrocephalus & 8 & $200 \pm 200$ & $N R$ & $\begin{array}{l}27 \\
12\end{array}$ & $\begin{array}{l}\text { Gr. } 1: 300 \pm 300 \text { (NS) } \\
\text { Gr. } 2: 500 \pm 300 \text { (NS) }\end{array}$ & $N R$ & 46 \\
\hline \multicolumn{8}{|l|}{ Infectious and inflammatory } \\
\hline Multiple sclerosis & 30 & 410 median & NR & 30 & 2810 median & NR & 49 \\
\hline Guillain-Barré syndrome & 30 & 410 median & NR & $\begin{array}{l}17 \\
20\end{array}$ & $\begin{array}{l}\text { Axonal: } 740 \text { median } \\
\text { ADIP: } 580 \text { median }\end{array}$ & NR & 49 \\
\hline \multicolumn{8}{|l|}{ Miscellaneous } \\
\hline Schizophrenia & 17 & $180 \pm 150$ & NR & 12 & $160 \pm 150$ (NS) & NR & 112 \\
\hline
\end{tabular}

All values have been converted to $\mathrm{ng} / \mathrm{l}$ to facilitate comparison. Unless otherwise noted, values are given as mean \pm SD. ADIP, acute demyelinating inflammatory neuropathy. ${ }^{A}$ Data were presented in graphical form, from which these are estimated values.

Some cells outside the CNS also express low levels of GFAP, particularly nonmyelinating Schwann cells and enteric glial cells. A recent report indicates that GFAP is elevated in serum (and CSF) of patients with both axonal and demyelinating forms of GuillainBarré syndrome (49), an adult-onset autoimmune disorder of the PNS of unknown etiology. It would be interesting to search for elevations of serum GFAP in other disorders where there are suspected abnormalities of peripheral GFAP-expressing cells, such as inflammatory bowel disease (50).

\section{Neuronal IFs and disease}

The major neuronal IF proteins in both the CNS and the PNS are the NFTPs (NFL, NFM, and NFH). In the CNS, $\alpha$-internexin is also abundantly expressed in the same filament system as the NFTPs, whereas in the PNS, another neuronal IF protein, peripherin, is expressed (Figure 1). Neuronal IFs form the major structure in the axon, and axon diameter correlates with neuronal IF content. In a number of neurodegenerative diseases, large accumulations of neuronal IFs, known as spheroids, have been observed in neuronal cell bodies, as well as in axons.

Knockout and overexpression of neuronal IFs. To determine the importance of neuronal IFs in human neurodegenerative diseases, the genes encoding the major neuronal IF proteins have been knocked out in mice as well as overexpressed. Surprisingly, mice lacking neuronal IFs cannot readily be distinguished from their wild-type or heterozygous littermates, although they exhibit various degrees of reductions in axonal caliber and changes in spacing between the neuronal IFs (Table 3). These knockout mice have been described in more detail elsewhere (51), and we only summarize the most salient features here. NFL-deficient mice exhibit reduced axonal diameter and age-related death of approximately $20 \%$ of motor axons (52). Mice lacking some of the other neuronal
IF proteins also exhibit changes in axonal diameter (Table 3) (see also refs. 51,53). The relationship between the phenotypes of these neuronal IF protein-deficient mice and human diseases is not evident, since no reports of humans lacking any of the neuronal IF proteins have been reported to date. However, in the mutant quail quiver, the absence of NFL, and therefore the absence of neuronal IFs, leads to the "quivering" phenotype (54), suggesting that the absence of neuronal IFs in humans would lead to much more severe symptoms than in mice.

Since neurofilamentous inclusions are major hallmarks of a number of different neurodegenerative diseases, mouse and human NFTPs have been overexpressed in transgenic mice (Table 3). Overexpression in mice of human NFTPs can lead to neuronal dysfunction. Levels of expression may be important in determining the severity of the phenotypes. In general, less serious effects are seen with the overexpression of mouse NFTPs, and the overexpression of multiple neuronal IF proteins can lead to increased radial diameter (reviewed in ref. 51). A dominant negative mutant NFH, when overexpressed in mice, led to perikaryal neurofilamentous accumulations due to a block of transport of neuronal IFs into the axon (55). Axon diameter was reduced, and some Purkinje cell death was observed in older mice (56). Interestingly, both peripherin and $\alpha$-internexin overexpression lead to neurodegeneration and neuronal cell death $(57,58)$. The possible relationship between these two neuronal IFs and neurodegeneration is discussed later. The expression of a mutant NFL in which a leucine residue in the rod domain was mutated to proline resulted in abnormal accumulations and degeneration of spinal motor neurons. Finally, studies from Willim Schlaepfer's laboratory suggest that there is an element in the 3' UTR of NEFL (the official name for the gene encoding NFL) that when mutated results in motor impairment in transgenic mice (59). p190RhoGEF, an RNA- 


\section{Table 3}

Phenotypes of mice lacking neuronal IF proteins and mice overexpressing neuronal IF proteins

\begin{tabular}{|c|c|c|}
\hline IF protein & Phenotype & Ref. \\
\hline \multicolumn{3}{|c|}{ Mice lacking neuronal IF proteins } \\
\hline NFL & $\begin{array}{l}\text { Absence of axonal IFs, decrease in axon caliber; abnormal axon conductance. Decreases in both NFM and NFH. } \\
\text { Loss of motor neurons (approximately 20\%) and delayed maturation of regenerating myelinated axons. } \\
\text { Increase in microtubule content. }\end{array}$ & 52 \\
\hline NFM & $\begin{array}{l}\text { Decrease in radial growth of large myelinated axons. Decrease in IF content. Decrease in NFL; increase } \\
\text { in NFH. Atrophy of motor neurons and hind limb paralysis with aging. Increase in microtubule content. }\end{array}$ & 113,114 \\
\hline NFH & Small reduction in radial growth. Little reduction in spacing between neurofilaments. & 115 \\
\hline NFM and NFH & More severe reduction in radial growth than lack of NFM alone. Unassembled NFL in perikarya. & 116 \\
\hline Peripherin & Reduced number of unmyelinated sensory axons. Increased levels of $\alpha$-internexin in ventral roots. & 117 \\
\hline$\alpha$-Internexin & No effect on axonal caliber. No neuronal defects. & 118 \\
\hline \multicolumn{3}{|c|}{ Mice expressing truncated neuronal IF proteins } \\
\hline NFH-tail $\Delta$ & No effect on axonal diameter; slower radial growth. No change in interfilament spacing. & 119 \\
\hline NFM-tail $\Delta$ & Reduction in radial growth similar to NFM deficiency. Reduced spacing between neurofilaments. & 120 \\
\hline \multicolumn{3}{|c|}{ Mice overexpressing neuronal IF proteins } \\
\hline NFL (mouse) & $\begin{array}{l}\text { Massive accumulations of neurofilaments in ventral horn motor neurons accompanied by increased axonal } \\
\text { degeneration, proximal axon swelling, and severe skeletal muscle atrophy. }\end{array}$ & 121 \\
\hline NFM (mouse) & Reduction in radial growth. No change in interfilament distance. & 122 \\
\hline NFH (mouse) & Reduction in radial growth. No change in interfilament distance. & 116,123 \\
\hline$N F L+N F M ; N F L+N F H$ & Increase in radial growth. & 116 \\
\hline NFL (human) & Perikaryal accumulations in the thalamus. & 124 \\
\hline NFM (human) & Neuronal dysfunction and motor neuron loss. Neurofilamentous swellings (depending on level). & $125-127$ \\
\hline NFH (human) & $\begin{array}{l}\text { Abnormal neurofilamentous swellings in cell bodies and proximal axons. Skeletal muscle atrophy. } \\
\text { Motor dysfunction. No motor neuron loss. }\end{array}$ & 128 \\
\hline Peripherin & $\begin{array}{l}\text { Selective degeneration of motor axons during aging. Overexpression of peripherin in NFL null mice leads } \\
\text { to early-onset formation of IF inclusions and selective death of spinal motor neurons }\end{array}$ & 129 \\
\hline$\alpha$-Internexin & Cerebellar torpedoes/Purkinje cell degeneration. & 58 \\
\hline $\begin{array}{l}\text { Mutant NFL } \\
\text { (rod domain mutation) }\end{array}$ & $\begin{array}{l}\text { Degeneration of motor neuron. Abnormal axonal and perikaryal accumulations of IFs. } \\
\text { Atrophy of skeletal muscles. }\end{array}$ & 130 \\
\hline $\begin{array}{l}\text { Mutant NFL } \\
\text { (3' UTR mutation) }\end{array}$ & Impairment of motor function. Atrophy of nerve fibers in the ventral root. & 59 \\
\hline
\end{tabular}

binding protein that binds to this $3^{\prime}$ UTR regulates the stability of NFL-encoding mRNA and interacts with NFL proteins as well. p190RhoGEF also colocalizes with aggregates of NFL subunits in degenerating motor neurons, providing a link among aggregation, expression of NFL, and motor neuron disease (60). Posttranscriptional regulatory mechanisms have been implicated in controlling expression of neuronal IF proteins both in normal development and in neurodegenerative disease. These mechanisms are described in more detail in a recent review (61).

Neuronal IF inclusion disease. A recently described disease that involves neuronal IFs is neuronal IF inclusion disease (NIFID). This disease was first described in 2004 in a series of reports by Cairns et al. $(62,63)$. Microscopically, this disease is characterized by neuronal IF inclusions that contain neither synuclein nor tau. Thus, NIFID is clearly distinguished from other diseases that involve filamentous inclusions, such as synucleinopathies (e.g., Parkinson disease and multiple system atrophy), tauopathies (e.g., Alzheimer disease and frontotemporal dementia and parkinsonism linked to chromosome 17 [FTDP-17]), and motor neuron disease. The inclusions in NIFID are unusual in that $\alpha$-internexin has been found to be a major component. Although $\alpha$-internexin immunoreactivity has been observed in other neurodegenerative disorders, it is generally a relatively minor component of the pathological neuronal inclusions in these diseases. The prominent clinical phenotype of NIFID is frontotemporal dementia, and the most common symptoms are behavioral and personality changes. Language impairment, perseveration, executive dysfunction, hyperreflexia, and primitive reflexes are frequent signs of the disease. Histological changes are extensive in many cortical areas, deep gray matter, cerebellum, and spinal cord. In the initial reports of the disease, the mean age of onset was 40.8 years, and the mean age of death was 45.3. However a recent report described a patient who developed the disease at 70 years of age (64). The number of cases of NIFID is still small, and no genetic mutations leading to NIFIDs have been described. However, it is interesting to note that gigaxonin-deficient mice have $\alpha$-internexin-positive inclusions that have been described as highly reminiscent of the inclusions found in human NIFID (65).

Overexpression of $\alpha$-internexin in transgenic mice leads to neurofilamentous inclusions in the large pyramidal neurons of the neocortex and in the ventral anterior and posteromedial nuclei of the thalamus (58). However, the most obvious pathology in these mice is found in the cerebellum, where numerous swellings of the proximal portions of the axons of Purkinje cells have been observed. These swellings, known as torpedoes, are filled with massive disoriented neuronal IFs. The mice have a deficit in motor coordination that correlates with the morphological changes in Purkinje cells. Furthermore, the neurofilamentous inclusions lead to progressive loss of neurons in aged transgenic mice that is dependent on the 


\section{Table 4}

Forms of CMT and their genetic cause

\begin{tabular}{|c|c|}
\hline Form of CMT & Affected gene \\
\hline \multicolumn{2}{|c|}{ Autosomal or X-linked dominant demyelinating disease } \\
\hline CMT1A & PMP22 (duplication) \\
\hline CMT1B & LITAF \\
\hline CMT1C & EGFR2 \\
\hline CMT1D & GJB1 \\
\hline CMT1E & NEFL \\
\hline CMT1X & $M P Z$ \\
\hline \multicolumn{2}{|c|}{ Autosomal dominant axonal disease } \\
\hline СMT2A & KIF1B $\beta$ \\
\hline СMT2B & $R A B 7$ \\
\hline CMT2D & GARS \\
\hline CMT2E & NEFL \\
\hline CMT2F & HSPB1 \\
\hline CMT2L & HSPB8 \\
\hline СMT2-P0 & $M P Z$ \\
\hline \multicolumn{2}{|c|}{ Dominant intermediate disease } \\
\hline DI-CMTA & Unknown \\
\hline DI-CMTB & DNM2 \\
\hline DI-CMTC & YARS \\
\hline DI-CMTD & $M P Z$ \\
\hline
\end{tabular}

Autosomal dominant or recessive severe demyelinating disease; CMT3 DSS Dominant (PMP22, MPZ, GJB1); recessive (MTMR2 and PRX) CHN Dominant (EGR2, PMP22 and MPZ) and recessive (EGR2)

$\begin{array}{lc}\text { Autosomal recessive demyelinating disease } \\ \text { CMT4A } & \text { GDAP1 } \\ \text { CMT4B } & \text { MTMR2 } \\ \text { CMT4C } & \text { MTMR13 } \\ \text { CMT4D } & N D R G 1 \\ \text { CMT4F } & P R X \\ \text { CMT4 } & E G R 2\end{array}$

Autosomal recessive axonal disease

$\begin{array}{ll}\text { CMT2A } & \text { LMNA } \\ \text { CMT2K } & \text { GDAP1 }\end{array}$

$C H N$, congenital hypomyelinating neuropathy; DSS, Dejerine-Sottas syndrome; DNM2, dynamin2; EGR2, early growth-response 2; GARS, glycyl transfer RNA synthetase; GDAP, ganglioside-induced differentiation-associated protein; GJB1, gap junction membrane channel protein $\beta 1 ; K I F$, kinesin family member; LITAF, lipopolysaccharide-induced TNF- $\alpha$ factor; $L M N A$, lamin A/C; $M P Z$, myelin protein 0; NDRG, N-myc downstream-regulated gene; $P O$, myelin protein $0 ; P M P$, peripheral myelin protein; $P R X$, periaxin. Adapted from ref. 73.

level of $\alpha$-internexin overexpression. Other correlations between the presence of torpedoes and cerebellar disorders have been made primarily in animal models $(66,67)$. However, it is interesting to note that an increased number of cerebellar torpedoes have been observed in a subtype of essential tremor, a syndrome characterized by a slowly progressive postural and/or kinetic tremor that is present in as many as $23 \%$ of individuals more than 65 years old $(68,69)$. This abundance of cerebellar torpedoes could ultimately lead to Purkinje cell loss, suggesting that essential tremor could be of potential interest in the studies of neuronal IF dysfunctions.

Charcot-Marie-Tooth disease. Studies in transgenic mice have suggested that overexpression of neuronal IF proteins can result in neurofilamentous inclusions. However, not all of these inclusions lead to neurodegeneration (Table 3). The direct relationship between mutations in the genes encoding neuronal IF proteins and neurodegeneration has until recently been unresolved. It was therefore of considerable interest when mutations in NEFL were correlated with the neurodegenerative disease CharcotMarie-Tooth disease (CMT) (70, 71).

CMT is an inherited peripheral neuropathy that has been linked to mutations in multiple genes $(72,73)$. It is a highly prevalent sensory and motor neuropathy, with approximately 1 per 2,500 people affected in the general population worldwide. The disease was originally subclassified into CMT1 and CMT2 based on nerve-conduction velocity (NCV): CMT1 patients have a reduced NCV, whereas CMT2 patients have relatively normal NCV. CMT1 is generally a demyelinating neuropathy, whereas CMT2 is axonal. The existing clinical overlap between different types of CMT suggests a common pathogenic mechanism, and there is a relationship between demyelination and axonal degeneration. Both these forms of CMT are slowly progressive bilateral neuropathies with distal predominance; patients lose the normal use of their limbs, as nerves to the extremities degenerate. Patients show a high degree of heterogeneity, both in the clinical presentation and the genetic level. Mutations in a number of genes important for myelin formation and maintenance have generally been identified as causing CMT1 as well as CMT3 and CMT4 (CMT3 is a particularly severe demyelinating form of CMT, whereas CMT4 is an autosomal recessive form) (Table 4). These include mutations in peripheral myelin protein 22 $(P M P 22)$, myelin protein $0(P 0)$, gap junction membrane channel protein $\beta 1$ (GJB1, also known as connexin 32), and early growth-response 2 (EGR2), which encodes a transcription factor that binds to the GJB1 promoter (reviewed in ref. 73). The first gene found to be associated with CMT2 was NEFL, and this association was observed in two different families resulting from two different mutations $(70,71)$. Other mutations that cause CMT2 are listed in Table 4.

These first two CMT-associated NEFL mutations encode changes in the rod domain (Q333P) and the head domain (P8R) of NFL (Figure 1). The two mutations were found to cause disruption of filament assembly in transfected nonneuronal cells (74). This effect was dominant, since wild-type NFL could not rescue the assembly defect. Furthermore, in transfected cultured neuronal cells, the two mutations also affected both slow and fast anterograde and retrograde axonal transport and perturbed the localization and transport of mitochondria $(75,76)$. Mutant NFL also caused the fragmentation of the Golgi apparatus and increased neuritic degeneration. Although these studies were done in cells overexpressing the mutant proteins, the dominant effects are consistent with the disease, suggesting that generalized defects in axonal transport could be responsible for this neuropathy.

Since the first two CMT-linked NEFL mutations were described, additional mutations in NEFL have been identified both in families and in individual CMT cases (77). These mutations primarily encode changes in the head and rod domain. Two mutations that were described in the tail domain turned out not to be pathogenic. Patients with NEFL mutations are generally classified as having CMT2E (although some have been classified as having CMT1F), because of a markedly reduced NCV more typical of CMT1. The mutations lead to disease with different ages of onset and sever- 
ity. Electron micrographs from patients with $d x$ mutations show pathological hallmarks characteristic of CMT, including concentric sheaths ("onion bulbs") that are consistent with a myelination defect $(77,78)$. This suggests crosstalk between the mutant NFL in the axon and the surrounding myelin. EM studies from patients with other NEFL mutations show giant axons, i.e., axonal swellings surrounded by an extremely thin myelin sheet, and in one case many myelinated fibers consisting exclusively of microtubules with few or absent neuronal IFs (79) (Figure 2, C and D). The pathology overlaps with the previously described GAN, which is also classified as a neuronal CMT (72).

A number of CMT-associated NEFL mutations have been tested for their ability to self assemble and coassemble with wild-type NFTPs (80). The results showed that all pathogenic mutations disrupted the assembly and transport of neuronal IFs. Transfection experiments have been helpful in determining whether a mutation is pathogenic. In one study, two unrelated patients were identified with the same mutation in the rod domain (I214M) (81). Transfection studies showed no abnormalities in filament assembly, and one of these patients had a sibling who did not carry the NEFL I214M mutation but still developed CMT. Therefore this mutation is unlikely to be the main cause of CMT in these two patients, although it is possible that it was an additional risk factor for the disease. In another case, a duplication/insertion mutation in NEFL in a patient with CMT resulted in expression of a truncated NFL protein that contained only a portion of the head domain (82). This truncated NFL was apparently sufficient to disrupt neurofilament assembly in transfected cells. A large-scale study on CMT patients has determined that mutations in NEFL are responsible for approximately $2 \%$ of CMT cases and a high percentage of CMT2 cases (77).

Mutations in the genes encoding two proteins that can interact with neurofilaments have also been shown to cause CMT. HSPB1 (also known as Hsp27) has been reported to interact with a number of IF proteins and influence their assembly. Mutations in HSPB1 have been reported to cause a new subtype of the axonal form of CMT, CMT2F (83). In cotransfection experiments, mutant HSPB1 was found to have an inhibitory effect on the assembly of NFL in transfected cells. Further studies in cultured motor neurons showed that the coexpression of wild-type HSPB1 diminished the aggregation of CMT mutant NFL, whereas the expression of mutant HSPB1 resulted in progressive degeneration of motor neurons as well as disruption of the neurofilament network, consistent with studies in nonneuronal cells (84). A second protein that interacts with NFL and has been linked to CMT is myotubularin-related protein 2 (MTMR2) (85). Mutations in MTMR2 cause a subtype of CMT, called CMT4B (Table 4), and mutant MTMR2 induces abnormal NFL assembly in transfected cells (86). It should be noted that mice lacking MTMR2 develop a CMT-like neuropathy, including several characteristics of dysmyelination (87). This same phenotype was observed following Schwann cell-specific MTMR2 inactivation, whereas neuron-specific inactivation did not result in an obvious phenotype (88). As described before, NFLdeficient mice do not exhibit a CMT-like neuropathy (52). However, despite their apparently normal appearance, they do exhibit loss of motor neurons and markedly reduced axon diameters; it is therefore possible that the NFL assembly defects induced by disease-linked MTMR2 mutations could contribute to the pathogenesis of CMT4B in humans.

Amyotrophic lateral sclerosis. One disease in which neurofilamentous accumulations have long been described is amyotrophic lateral sclerosis (ALS, often known as Lou Gehrig's disease) (89, 90), a progressive, fatal neurodegenerative disease caused by the degeneration of motor neurons. Motor neurons in patients with ALS accumulate protein aggregates of neuronal IFs, spheroids, in the perikarya and axons. Because of the presence of neuronal IFs in these spheroids, several studies have searched for mutations in the genes encoding NFTPs and there are reports of codon deletions in the tail domain of NFH in sporadic ALS cases as well as some potential mutations in the tail domain of $\operatorname{NFM}(91,92)$. However, no mutations in genes encoding NFTPs have been identified in familial cases of ALS, and there are no published reports of assembly studies in cells transfected with the putative sporadic ALS NFH and NFM mutants. Superoxide dismutase 1 (SOD1) is mutated in $10 \%$ of familial cases of ALS, and the association of neurofilaments and SOD1 has been studied in a number of transgenic mouse models. There are a number of excellent review articles on this association, and we therefore do not discuss them here (see, for example, refs. 51, 93). Instead, we limit our discussion to the most recent studies describing the linkage between ALS and peripherin mutations.

Peripherin has been found in spheroids of motor neuron disease together with neurofilaments (94). Furthermore, peripherinpositive Lewy body-like inclusions, a type of cytoplasmic inclusion that usually contains $\alpha$-synuclein and is abundant in the brains of patients with Parkinson disease, have been observed in motor neuron perikarya of 9 of 40 ALS cases (and not in controls). These inclusions do not express $\alpha B$-crystallin, NFTPs, $\alpha$-internexin, actin, or $\alpha$-synuclein (95). Peripherin overexpression in transgenic mice results in late-onset motor neuron disease (Table 3 ). This defect is exacerbated if the mice also lack NFL.

Several additional studies point to a role for peripherin in ALS. A recently identified splice variant of mouse peripherin that results in an aberrant peripherin protein has been linked to ALS (96). This form of peripherin includes intron 4, which is spliced out of the most abundant form of the protein, keeping the reading frame and thereby resulting in a larger form of peripherin (Per61) (Figure 1). An antibody specific for a peptide encoded by this intron stains the filamentous inclusions in the SOD mutant mouse model of ALS and also axonal spheroids in tissue from individuals with ALS. The latter result is puzzling, since inclusion of human intron 4 would lead to a truncated protein unless there is also a frame shift. In a later study, a novel human peripherin transcript that retains both introns 3 and 4, which are spliced out of the most abundant form of human peripherin, resulting in a truncated peripherin (Per28), was described (Figure 1). Per28 was upregulated at both the protein and mRNA levels in a case of human ALS, and an antibody specific for Per28 stained the filamentous inclusions (97). These studies suggest that missplicing of peripherin could lead to disease. These are very intriguing results that should be followed up.

Additional reports have also implicated mutations in peripherin with ALS. These studies include sequencing the peripherin gene in sporadic and familial ALS cases. In one study, eighteen polymorphic variants were detected in both ALS and control populations, and two variants were discovered only in ALS cases (98). One of these variants consists of a single base pair deletion in exon 1 of the peripherin gene that generates a truncated peripherin of 85 amino acids. This truncated peripherin disrupts neuronal IF assembly in transfected cells, similar to the CMT-linked truncated NFL mutant described above (82). One of the variants described 
in this study was also identified in a second study. In this case, the patient had this variant in both copies of peripherin (99). Assembly studies suggested that this peripherin variant was not sufficient to cause assembly defects by itself, but the variant could not self assemble, consistent with the fact that the patient had both copies of peripherin mutated.

\section{Concluding comments and future directions}

In this review, we have described some of the recent evidence of the roles that dysfunctions of IFs of neurons and glial cells may play in neurodegenerative diseases. Transgenic mouse models have been somewhat helpful in delineating the course of these diseases, although the results of knockouts and overexpression of normal and mutated IF proteins in transgenic mice have not always been completely clear-cut. A number of investigations regarding the roles of IF proteins are being pursued. Among these are the roles of the links between the various cytoskeletal elements as well as the role that IF proteins may play in signaling. Interactions between IFs and plakin proteins, which link cytoskeletal elements together and connect them to cell junctions, are known to occur and have now also been observed for GFAP and plectin (19). Other plakins are expressed in the nervous system and may also interact with IF proteins. In an in vitro study, PKCE was shown to associate with peripherin by immunoprecipitation and induce its aggregation. This aggregation was coupled with an increase of apoptosis, and both aggregation and apoptosis could be suppressed using siRNAs to PKCE (100). Keratin IFs have been shown to be regulators of key signaling pathways that control cell survival and cell growth (101). We would expect that IF proteins in neurons and glial cells could also play similar roles, and these are areas that are open for future investigations. Although not described in detail in this Review, recent studies on mRNA stability of neuronal IFs and their link to neurodegeneration clearly are also areas open for future work (61).

The involvement of IF proteins in neurodegenerative diseases leads to the obvious question as to potential therapeutics. To screen potential drugs, cell-culture systems expressing mutant IF proteins resulting in aggregates are possible starting points. If compounds that can alleviate these aggregates can be identified, the transgenic mouse models would be helpful in determining whether these compounds work in a whole animal. Additional transgenic mouse models are also still needed; for example, there are no published mice expressing the mutant forms of NFL that cause CMT2.

\section{Acknowledgments}

This work was supported by grants from the NIH (NS42803 and NS060120 to A. Messing; NS15182 to R.K.H. Liem; and HD03352 to the Waisman Center) and by the Juanma and Palamaro Funds (to A. Messing). We thank Daniel Cheng for his help in preparing Figure 1.

Address correspondence to: Ronald K.H. Liem, Department of Pathology and Cell Biology, Taub Institute for Research on Alzheimer's Disease and the Aging Brain, Columbia University College of Physicians and Surgeons, New York, New York, USA. Phone: (212) 305-4078; Fax: (212) 305-5498; E-mail: rkl2@columbia.edu. Or to: Albee Messing, Waisman Center and Department of Comparative Biosciences, University of Wisconsin, Madison, Wisconsin, USA. Phone: (608) 263-9191; Fax: (608) 263-4364; E-mail: messing@waisman.wisc.edu.
1. Ching, G.Y., and Liem, R.K.H. 2006. Neuronal intermediate filaments and neurodegenerative diseases. Landes Bioscience. Austin, Texas, USA. 35-51.

2. Brenner, M., Goldman, J.E., Quinlan, R.A., and Messing, A. 2008. Alexander disease: a genetic disorder of astrocytes. In Astrocytes in pathophysiology of the nervous system. V.H. Parpura and P.G. Haydon, editors. Springer. Boston, Massachusetts, USA. 591-648.

3. Quinlan, R.A., Brenner, M., Goldman, J., and Messing, A. 2007. GFAP and its role in Alexander disease. Exp. Cell Res. 313:2077-2087.

4. Alexander, W.S. 1949. Progressive fibrinoid degeneration of fibrillary astrocytes associated with mental retardation in a hydrocephalic infant. Brain. 72:373-381.

5. Li, R., et al. 2005. GFAP mutations in infantile, juvenile, and adult forms of Alexander disease. Ann. Neurol. 57:310-326.

6. Szeverenyi, I., et al. 2008. The human intermediate filament database: Comprehensive information on a gene family involved in many human diseases. Hum. Mutat. 29:351-360.

7. Hagemann, T.L., Connor, J.X., and Messing, A 2006. Alexander disease-associated glial fibrillary acidic protein mutations in mice induce Rosenthal fiber formation and a white matter stress response. J. Neurosci. 26:11162-11173.

8. Hagemann, T.L., et al. 2005. Gene expression analysis in mice with elevated glial fibrillary acidic protein and Rosenthal fibers reveals a stress response followed by glial activation and neuronal dysfunction. Hum. Mol. Genet. 14:2443-2458.

9. Tang, G., Xu, Z., and Goldman, J.E. 2006. Synergistic effects of the SAPK/JNK and the proteasome pathway on glial fibrillary acidic protein (GFAP) accumulation in Alexander disease. J. Biol. Chem. 281:38634-38643.
10. Cho, W., and Messing, A. 2009. Properties of astrocytes cultured from GFAP over-expressing and GFAP mutant mice. Exp. Cell Res. 315:1260-1272.

11. DeArmond, S.J., Lee, Y., Kretzschmar, H.A., and Eng, L.F. 1986. Turnover of glial filaments in mouse spinal cord. J. Neurochem. 47:1749-1753.

12. Morgan, T.E., et al. 1997. Increased transcription of the astrocyte gene GFAP during middle-age is attenuated by food restriction: implications for the role of oxidative stress. Free Radic. Biol. Med. 23:524-528.

13. Webb, J.L., Ravikumar, B., Atkins, J., Skepper, J.N., and Rubinsztein, D.C. 2003. a-Synuclein is degraded by both autophagy and the proteasome. J. Biol. Chem. 278:25009-25013.

14. Tang, G., et al. 2008. Autophagy induced by Alexander disease-mutant GFAP accumulation is regulated by $\mathrm{p} 38 / \mathrm{MAPK}$ and $\mathrm{mTOR}$ signaling pathways. Hum. Mol. Genet. 17:1540-1555.

15. Tannous, P., et al. 2008. Autophagy is an adaptive response in desmin-related cardiomyopathy. Proc. Natl. Acad. Sci. U. S. A. 105:9745-9750.

16. Zemke, D., Azhar, S., and Majid, A. 2007. The mTOR pathway as a potential target for the development of therapies against neurological disease. Drug News Perspect. 20:495-499.

17. Hsiao, V.C., et al. 2005. Alexander-disease mutation of GFAP causes filament disorganization and decreased solubility of GFAP. J. Cell Sci. 118:2057-2065

18. Perng, M.D., et al. 2008. Glial fibrillary acidic protein filaments can tolerate the incorporation of assembly-compromised GFAP-delta, but with consequences for filament organization and aB-crystallin association. Mol. Biol. Cell. 19:4521-4533.

19. Tian, R., Gregor, M., Wiche, G., and Goldman, J.E. 2006. Plectin regulates the organization of glial fibrillary acidic protein in Alexander disease. Am.
J. Pathol. 168:888-897.

20. Roelofs, R.F., et al. 2005. Adult human subventricular, subgranular, and subpial zones contain astrocytes with a specialized intermediate filament cytoskeleton. Glia. 52:289-300.

21. Hagemann, T., Boelens, W., Wawrousek, E., and Messing, A. 2009. Suppression of GFAP toxicity by alphaB-crystallin in mouse models of Alexander disease. Hum. Mol. Genet. 18:1190-1199.

22. Berg, B.O., Rosenberg, S.H., and Asbury, A.K. 1972. Giant axonal neuropathy. Pediatrics. 49:894-899.

23. Bomont, P., et al. 2000. The gene encoding gigaxonin, a new member of the cytoskeletal BTB/kelch repeat family, is mutated in giant axonal neuropathy. Nat. Genet. 26:370-374.

24. Allen, E., et al. 2005. Gigaxonin-controlled degradation of MAP1B light chain is critical to neuronal survival. Nature. 438:224-228.

25. Kretzschmar, H.A., Berg, B.O., and Davis, R.L. 1987. Giant axonal neuropathy: a neuropathological study. Acta Neuropathol. 73:138-144.

26. Prineas, J.W., Ouvrier, R.A., Wright, R.G., Walsh, J.C., and McLeod, J.G. 1976. Giant axonal neuropathy - a generalized disorder of cytoplasmic microfilament formation. J. Neuropathol. Exp. Neurol. 35:458-470.

27. Thomas, C., Love, S., Powell, H.C., Schultz, P., and Lampert, P.W. 1987. Giant axonal neuropathy: correlation of clinical findings with postmortem neuropathology. Ann. Neurol. 22:79-84.

28. Bomont, P., and Koenig, M. 2003. Intermediate filament aggregation in fibroblasts of giant axonal neuropathy patients is aggravated in non dividing cells and by microtubule destabilization. Hum. Mol. Genet. 12:813-822.

29. Peiffer, J., Schlote, W., Bischoff, A., Boltshauser, E., and Müller, G. 1977. Generalized giant axonal neuropathy: a filament-forming disease of neuronal, 
endothelial, glial, and schwann cells in a patient without kinky hair. Acta Neuropathol. 40:213-218.

30. Kumar, K., Barre, P., Nigro, M., and Jones, M.Z. 1990. Giant axonal neuropathy: clinical, electrophysiologic, and neuropathologic features in two siblings. J. Child Neurol. 5:229-234.

31. van der Knaap, M.S., and Valk, J. 2005. Magnetic resonance of myelin and myelin disorders. 3rd edition. Springer. Berlin, Germany. 1084 pp.

32. Dequen, F., Bomont, P., Gowing, G., Cleveland, D.W., and Julien, J.P. 2008. Modest loss of peripheral axons, muscle atrophy and formation of brain inclusions in mice with targeted deletion of gigaxonin exon 1. J. Neurochem. 107:253-264.

33. Albrechtsen, M., Sorensen, P.S., Gjerris, F., and Bock, E. 1985. High cerebrospinal fluid concentration of glial fibrillary acidic protein (GFAP) in patients with normal pressure hydrocephalus. J. Neurol. Sci. 70:269-274.

34. Blennow, M., Savman, K., Ilves, P., Thoresen, M., and Rosengren, L. 2001. Brain-specific proteins in the cerebrospinal fluid of severely asphyxiated newborn infants. Acta Paediatrica. 90:1171-1175.

35. Fukuyama, R., Izumoto, T., and Fushiki, S. 2001. The cerebrospinal fluid level of glial fibrillary acidic protein is increased in cerebrospinal fluid from Alzheimer's disease patients and correlates with severity of dementia. Eur. Neurol. 46:35-38.

36. Petzold, A., et al. 2004. An ELISA for glial fibrillary acidic protein. J. Immunol. Methods. 287:169-177.

37. Ahlsén, G., et al. 1993. Glial fibrillary acidic protein in the cerebrospinal fluid of children with autism and other neuropsychiatric disorders. Biol. Psychiatry. 33:734-743.

38. Rosengren, L.E., et al. 1992. A sensitive ELISA for glial fibrillary acidic protein: Application in CSF of children. J. Neurosci. Methods. 44:113-119.

39. Lafon-Cazal, M., et al. 2003. Proteomic analysis of astrocytic secretion in the mouse - Comparison with the cerebrospinal fluid proteome. J. Biol. Chem. 278:24438-24448.

40. Tullberg, M., Rosengren, L., Blomsterwall, E., Karlsson, J.E., and Wikkels, C. 1998. CSF Neurofilament and glial fibrillary acidic protein in normal pressure hydrocephalus. Neurology. 50:1122-1127.

41. Blennow, M., et al. 1996. Glial fibrillary acidic protein is increased in the cerebrospinal fluid of preterm infants with abnormal neurological findings. Acta Paediatr. 85:485-489.

42. Norgren, N., et al. 2004. Neurofilament and glial fibrillary acidic protein in multiple sclerosis. Neurology. 63:1586-1590.

43. Petzold, A., et al. 2006. Early identification of secondary brain damage in subarachnoid hemorrhage: A role for glial fibrillary acidic protein. J. Neurotrauma. 23:1179-1184.

44. Misu, T., et al. 2009. Marked increase in cerebrospinal fluid glial fibrillar acidic protein in neuromyelitis optica: an astrocytic damage marker. J. Neurol. Neurosurg. Psychiatry. 80:575-577.

45. Kyllerman, M., Rosengren, L., Wiklund, L., and Holmberg, E. 2005. Increased levels of GFAP in the cerebrospinal fluid in three subtypes of genetically confirmed Alexander disease. Neuropediatrics. 36:319-323.

46. Beems, T., et al. 2003. Serum- and CSF-concentrations of brain specific proteins in hydrocephalus. Acta Neurochirurgica. 145:37-43.

47. Steiner, J., Bielau, H., Bernstein, H., Bogerts, B., and Wunderlich, M. 2006. Increased cerebrospinal fluid and serum levels of S100B in first-onset schizophrenia are not related to a degenerative release of glial fibrillar acidic protein, myelin basic protein and neurone-specific enolase from glia or neurones. J. Neurol. Neurosurg. Psychiatry. 77:1284-1287.

48. Hsu, A.A., et al. 2008. Neurological injury markers in children with septic shock. Pediatr. Crit. Care Med. 9:245-251.
49. Notturno, F., Caporale, C.M., De Laurentis, A., and Uncini, A. 2008. Glial fibrillary acidic protein: A marker of axonal Guillain-Barre syndrome and outcome. Muscle Nerve. 38:899-903.

50. Savidge, T.C., Sofroniew, M.V., and Neunlist, M. 2007. Starring roles for astroglia in barrier pathologies of gut and brain. Lab. Invest. 87:731-736

51. Julien, J.P., and Beaulieu, J.M. 2000. Cytoskeletal abnormalities in amyotrophic lateral sclerosis: beneficial or detrimental effects? J. Neurol. Sci. 180:7-14.

52. Zhu, Q., Couillard-Despres, S., and Julien, J.P. 1997. Delayed maturation of regenerating myelinated axons in mice lacking neurofilaments. Exp. Neurol. 148:299-316.

53. Liem, R.K., and Leung, C.L. 2003. Neuronal intermediate filament overexpression and neurodegeneration in transgenic mice. Exp. Neurol. 184:3-8.

54. Toyoshima, I., et al. 2000. Massive accumulation of $\mathrm{M}$ and $\mathrm{H}$ subunits of neurofilament proteins in spinal motor neurons of neurofilament deficient Japanese quail, Quv. Neurosci. Lett. 287:175-178.

55. Eyer, J., and Peterson, A. 1994. Neurofilamentdeficient axons and perikaryal aggregates in viable transgenic mice expressing a neurofilament-betagalactosidase fusion protein. Neuron. 12:389-405.

56. Tu, P.H., et al. 1997. Selective degeneration fo Purkinje cells with Lewy body-like inclusions in aged NFHLACZ transgenic mice. J. Neurosci. 17:1064-1074.

57. Beaulieu, J.M., Nguyen, M.D., and Julien, J.P. 1999. Late onset death of motor neurons in mice overexpressing wild-type peripherin. J. Cell Biol. 147:531-544.

58. Ching, G.Y., Chien, C.L., Flores, R., and Liem, R.K. 1999. Overexpression of alpha-internexin causes abnormal neurofilamentous accumulations and motor coordination deficits in transgenic mice. J. Neurosci. 19:2974-2986.

59. Nie, Z., et al. 2002. Untranslated element in neurofilament mRNA has neuropathic effect on motor neurons of transgenic mice. J. Neurosci. 22:7662-7670.

60. Canete-Soler, R., and Schlaepfer, W.W. 2007. The complex relation between genotype and phenotype in motor neuron disease. Ann. Neurol. 62:8-14.

61. Thyagarajan, A., Strong, M.J., and Szaro, B.G 2007. Post-transcriptional control of neurofilaments in development and disease. Exp. Cell Res. 313:2088-2097.

62. Cairns, N.J., et al. 2004. alpha-Internexin aggregates are abundant in neuronal intermediate filament inclusion disease (NIFID) but rare in other neurodegenerative diseases. Acta Neuropathol. 108:213-223

63. Cairns, N.J., et al. 2004. alpha-internexin is present in the pathological inclusions of neuronal intermediate filament inclusion disease. Am. J. Pathol. 164:2153-2161.

64. Molina-Porcel, L., et al. 2008. Clinical and pathological heterogeneity of neuronal intermediate filament inclusion disease. Arch. Neurol. 65:272-275.

65. Dequen, F., Bomont, P., Gowing, G., Cleveland, D.W., and Julien, J.P. 2008. Modest loss of peripheral axons, muscle atrophy and formation of brain inclusions in mice with targeted deletion of gigaxonin exon 1. J. Neurochem. 107:253-264.

66. Abbott, L.C., Isaacs, K.R., and Heckroth, J.A. 1996. Co-localization of tyrosine hydroxylase and zebrin II immunoreactivities in Purkinje cells of the mutant mice, tottering and tottering/leaner. Neuroscience. 71:461-475.

67. Resibois, A., and Poncelet, L. 2004. Purkinje cell neuroaxonal dystrophy similar to nervous mutant mice phenotype in two sibling kittens. Acta Neuropathol. 107:553-558.

68. Benito-Leon, J., and Louis, E.D. 2006. Essential tremor: emerging views of a common disorder.
Nat. Clin. Pract. Neurol. 2:666-678; quiz 2p following 691.

69. Benito-Leon, J., and Louis, E.D. 2007. Clinical update: diagnosis and treatment of essential tremor. Lancet. 369:1152-1154.

70. De Jonghe, P., et al. 2001. Further evidence that neurofilament light chain gene mutations can cause Charcot-Marie-Tooth disease type 2E. Ann. Neurol. 49:245-249.

71. Mersiyanova, I.V., et al. 2000. A new variant of Charcot-Marie-Tooth disease type 2 is probably the result of a mutation in the neurofilament-light gene. Am. J. Hum. Genet. 67:37-46.

72. Berger, P., Young, P., and Suter, U. 2002. Molecular cell biology of Charcot-Marie-Tooth disease. Neurogenetics. 4:1-15.

73. Suter, U., and Scherer, S.S. 2003. Disease mechanisms in inherited neuropathies. Nat. Rev. Neurosci. 4:714-726.

74. Perez-Olle, R., Leung, C.L., and Liem, R.K. 2002. Effects of Charcot-Marie-Tooth-linked mutations of the neurofilament light subunit on intermediate filament formation. J. Cell Sci. 115:4937-4946.

75. Brownlees, J., et al. 2002. Charcot-Marie-Tooth disease neurofilament mutations disrupt neurofilament assembly and axonal transport. Hum. Mol. Genet. 11:2837-2844.

76. Perez-Olle, R., et al. 2005. Mutations in the neurofilament light gene linked to Charcot-Marie-Tooth disease cause defects in transport. J. Neurochem. 93:861-874.

77. Jordanova, A., et al. 2003. Mutations in the neurofilament light chain gene (NEFL) cause early onset severe Charcot-Marie-Tooth disease. Brain. 126:590-597.

78. Shin, J.S., et al. 2008. NEFL Pro22Arg mutation in Charcot-Marie-Tooth disease type 1. J. Hum. Genet. 53:936-940.

79. Fabrizi, G.M., et al. 2007. Charcot-Marie-Tooth disease type $2 \mathrm{E}$, a disorder of the cytoskeleton. Brain. 130:394-403.

80. Perez-Olle, R., Jones, S.T., and Liem, R.K. 2004. Phenotypic analysis of neurofilament light gene mutations linked to Charcot-Marie-Tooth disease in cell culture models. Hum. Mol. Genet. 13:2207-2220.

81. Kabzinska, D., et al. 2006. Is a novel I214M substitution in the NEFL gene a cause of Charcot-MarieTooth disease? Functional analysis using cell culture models. J. Peripher. Nerv. Syst. 11:225-231.

82. Leung, C.L., Nagan, N., Graham, T.H., and Liem, R.K. 2006. A novel duplication/insertion mutation of NEFL in a patient with Charcot-Marie-Tooth disease. Am. J. Med. Genet. A. 140:1021-1025.

83. Evgrafov, O.V., et al. 2004. Mutant small heat-shock protein 27 causes axonal Charcot-Marie-Tooth disease and distal hereditary motor neuropathy. Nat. Genet. 36:602-606.

84. Zhai, J., Lin, H., Julien, J.P., and Schlaepfer, W.W. 2007. Disruption of neurofilament network with aggregation of light neurofilament protein: a common pathway leading to motor neuron degeneration due to Charcot-Marie-Tooth disease-linked mutations in NFL and HSPB1. Hum. Mol. Genet. 16:3103-3116

85. Previtali, S.C., et al. 2003. Myotubularin-related 2 protein phosphatase and neurofilament light chain protein, both mutated in CMT neuropathies, interact in peripheral nerve. Hum. Mol. Genet. 12:1713-1723.

86. Goryunov, D., Nightingale, A., Bornfleth, L., Leung, C., and Liem, R.K. 2008. Multiple disease-linked myotubularin mutations cause NFL assembly defects in cultured cells and disrupt myotubularin dimerization. J. Neurochem. 104:1536-1552.

87. Bolino, A., et al. 2004. Disruption of Mtmr2 produces CMT4B1-like neuropathy with myelin outfolding and impaired spermatogenesis. J. Cell Biol. 167:711-721. 
88. Bolis, A., et al. 2005. Loss of Mtmr2 phosphatase in Schwann cells but not in motor neurons causes Charcot-Marie-Tooth type 4B1 neuropathy with myelin outfoldings. J. Neurosci. 25:8567-8577.

89. Carpenter, S. 1968. Proximal axonal enlargement in motor neuron disease. Neurology. 18:841-851.

90. Hirano, A., et al. 1984. Fine structural study of neurofibrillary changes in a family with amyotrophic lateral sclerosis. J. Neuropathol. Exp. Neurol. 43:471-480.

91. Al-Chalabi, A., et al. 1999. Deletions of the heavy neurofilament subunit tail in amyotrophic lateral sclerosis. Hum. Mol. Genet. 8:157-164.

92. Garcia, M.L., et al. 2006. Mutations in neurofilament genes are not a significant primary cause of non-SOD1-mediated amyotrophic lateral sclerosis. Neurobiol. Dis. 21:102-109.

93. Robertson, J., Kriz, J., Nguyen, M.D., and Julien, J.P. 2002. Pathways to motor neuron degeneration in transgenic mouse models. Biochimie. 84:1151-1160.

94. Corbo, M., and Hays, A.P. 1992. Peripherin and neurofilament protein coexist in spinal spheroids of motor neuron disease. J. Neuropathol. Exp. Neurol. 51:531-537.

95. He, C.Z., and Hays, A.P. 2004. Expression of peripherin in ubiquinated inclusions of amyotrophic lateral sclerosis. J. Neurol. Sci. 217:47-54.

96. Robertson, J., et al. 2003. A neurotoxic peripherin splice variant in a mouse model of ALS. J. Cell Biol. 160:939-949

97. Xiao, S., et al. 2008. An aggregate-inducing peripherin isoform generated through intron retention is upregulated in amyotrophic lateral sclerosis and associated with disease pathology. J. Neurosci. 28:1833-1840.

98. Gros-Louis, F., et al. 2004. A frameshift deletion in peripherin gene associated with amyotrophic lateral sclerosis. J. Biol. Chem. 279:45951-45956.

99. Leung, C.L., et al. 2004. A pathogenic peripherin gene mutation in a patient with amyotrophic lateral sclerosis. Brain Pathol. 14:290-296.

100.Sunesson, L., Hellman, U., and Larsson, C. 2008 Protein kinase Cepsilon binds peripherin and induces its aggregation, which is accompanied by apoptosis of neuroblastoma cells. J. Biol. Chem. 283:16653-16664.

101. Kim, S., Wong, P., and Coulombe, P.A. 2006. A keratin cytoskeletal protein regulates protein synthesis and epithelial cell growth. Nature. 441:362-365.

102. Messing, A., and Brenner, M. 2003. Alexander disease: GFAP mutations unify young and old. Lancet Neurol. 2:75.

103.Eng, L.F., Lee, Y.L., Kwan, H., Brenner, M., and Messing, A. 1998. Astrocytes cultured from transgenic mice carrying the added human glial fibrillary acidic protein gene contain Rosenthal fibers. J. Neurosci. Res. 53:353-360.
104.Nylén, K., et al. 2002. Cerebrospinal fluid neurofilament and glial fibrillary acidic protein in patients with cerebral vasculitis. J. Neurosci. Res. 67:844-851.

105.Aurell, A., et al. 1991. Determination of S-100 and glial fibrillary acidic protein concentrations in cerebrospinal fluid after brain infarction. Stroke. 22:1254-1261

106. Rosengren, L.E., Wikkels, C., and Hagberg, L. 1994. A sensitive ELISA for glial fibrillary acidic protein Application in CSF of adults. J. Neurosci. Methods. 51:197-204.

107. Wallin, A., Blennow, K., and Rosengren, L.E. 1996. Glial fibrillary acidic protein in the cerebrospinal fluid of patients with dementia. Dementia. 7:267-272.

108.Vissers, J.L.M., et al. 2006. Rapid immunoassay for the determination of glial fibrillary acidic protein (GFAP) in serum. Clin. Chim. Acta. 366:336-340.

109. Foerch, C., et al. 2006. Serum glial fibrillary acidic protein as a biomarker for intracerebral haemorrhage in patients with acute stroke. J. Neurol. Neurosurg. Psychiatr. 77:181-184

110.Nylén, K., et al. 2007. Serum glial fibrillary acidic protein is related to focal brain injury and outcome after aneurysmal subarachnoid hemorrhage. Stroke. 38:1489-1494.

111.Nylén, K., et al. 2006. Increased serum-GFAP in patients with severe traumatic brain injury is related to outcome. J. Neurol. Sci. 240:85-91.

112.Steiner, J., Bielau, H., Bernstein, H.G., Bogerts, B., and Wunderlich, M.T. 2006. Increased cerebrospinal fluid and serum levels of S100B in first-onset schizophrenia are not related to a degenerative release of glial fibrillar acidic protein, myelin basic protein and neurone-specific enolase from glia or neurones. J. Neurol. Neurosurg. Psychiatry. 77:1284-1287.

113.Elder, G.A., et al. 1998. Absence of the mid-sized neurofilament subunit decreases axonal calibers, levels of light neurofilament (NF-L), and neurofilament content. J. Cell Biol. 141:727-739.

114.Jacomy, H., Zhu, Q., Couillard-Despres, S., Beaulieu, J.M., and Julien, J.P. 1999. Disruption of type IV intermediate filament network in mice lacking the neurofilament medium and heavy subunits. J. Neurochem. 73:972-984.

115.Zhu, Q., Lindenbaum, M., Levavasseur, F., Jacomy, H., and Julien, J.P. 1998. Disruption of the NF-H gene increases axonal microtubule content and velocity of neurofilament transport: relief of axonopathy resulting from the toxin beta,beta'-iminodipropionitrile. J. Cell Biol. 143:183-193.

116.Xu, Z., et al. 1996. Subunit composition of neurofilaments specifies axonal diameter. J. Cell Biol. 133:1061-1069

117. Lariviere, R.C., Nguyen, M.D., Ribeiro-da-Silva, A., and Julien, J.P. 2002. Reduced number of unmy- elinated sensory axons in peripherin null mice. J. Neurochem. 81:525-532.

118.Levavasseur, F., Zhu, Q., and Julien, J.P. 1999. No requirement of alpha-internexin for nervous system development and for radial growth of axons. Brain Res. Mol. Brain Res. 69:104-112.

119.Rao, M.V., et al. 2002. Gene replacement in mice reveals that the heavily phosphorylated tail of neurofilament heavy subunit does not affect axonal caliber or the transit of cargoes in slow axonal transport. J. Cell Biol. 158:681-693.

120.Garcia, M.L., et al. 2003. NF-M is an essential target for the myelin-directed "outside-in" signaling cascade that mediates radial axonal growth. J. Cell Biol. 163:1011-1020.

121.Xu, Z., Cork, L.C., Griffin, J.W., and Cleveland, D.W. 1993. Increased expression of neurofilament subunit NF-L produces morphological alterations that resemble the pathology of human motor neuron disease. Cell. 73:23-33.

122.Wong, P.C., et al. 1995. Increasing neurofilament subunit NF-M expression reduces axonal NF-H, inhibits radial growth, and results in neurofilamentous accumulation in motor neurons. J. Cell Biol. 130:1413-1422.

123.Marszalek, J.R., et al. 1996. Neurofilament subunit NF-H modulates axonal diameter by selectively slowing neurofilament transport. J. Cell Biol. 135:711-724.

124.Ma, D., Descarries, L., Julien, J.P., and Doucet, G. 1995. Abnormal perikaryal accumulation of neurofilament light protein in the brain of mice transgenic for the human protein: sequence of postnatal development. Neuroscience. 68:135-149.

125.Gama Sosa, M.A., et al. 2003. Human midsized neurofilament subunit induces motor neuron disease in transgenic mice. Exp. Neurol. 184:408-419.

126.Lee, V.M., et al. 1992. Expression of human midsized neurofilament subunit in transgenic mice. Brain Res. Mol. Brain Res. 15:76-84.

127.Tu, P.H., et al. 1995. Overexpression of the human NFM subunit in transgenic mice modifies the level of endogenous NFL and the phosphorylation state of NFH subunits. J. Cell Biol. 129:1629-1640.

128. Cote, F., Collard, J.F., and Julien, J.P. 1993. Progressive neuronopathy in transgenic mice expressing the human neurofilament heavy gene: a mouse model of amyotrophic lateral sclerosis. Cell. 73:35-46.

129.Beaulieu, J.M., Nguyen, M.D., and Julien, J.P. 1999. Late onset of motor neurons in mice overexpressing wild-type peripherin. J. Cell Biol. 147:531-544.

130.Lee, M.K., Marszalek, J.R., and Cleveland, D.W. 1994. A mutant neurofilament subunit causes massive, selective motor neuron death: implications for the pathogenesis of human motor neuron disease. Neuron. 13:975-988. 